\title{
The Relationship between Organizational Power and Job Involvement and Their Impact on Achieving Strategic Objectives (An Empirical Study of Private Hospitals Managers' Perspectives in Erbil City, Kurdistan Region of Iraq)
}

\author{
Zana Majed Sadq \\ Department of Management and Accounting, Faculty of Humanities and Social Science Koya University, Kurdistan
} Region - F.R, Iraq

Department of Legal Administration, Collage of Business and Economics, Lebanese-French University, Kurdistan Region - F.R, Iraq

http://dx.doi.org/10.18415/ijmmu.v6i5.1159

\begin{abstract}
This study aims to examine the relationship between organizational power and job involvement and their impact on achieving strategic objectives starting with the study framework. This takes into account the nature of the correlation between the study's dimensions and variables of organizational power (structural power, prestige power, and expert power) and job involvement (emotional involvement, cognitive involvement, and behavioral involvement) as well as their impact on achieving strategic objectives which includes (innovation, productivity, and social responsibility). This study has found that there is a positive relationship between organizational power and job involvement and that there is an impact on the relationship between organizational power and job involvement on achieving strategic objectives. Based on the results, this study presents a set of recommendations such as the need to work on raising organizational power levels and to search for organizational factors. This could lead to the development of the level of organizational power as well as setting incentives and salaries that contribute to an increase in the rate of job involvement.
\end{abstract}

Keywords: Organizational Power; Job Involvement; Strategic Objectives

\section{Introduction}

Successful management in any organization has a sincere professional desire to achieve success and continuously develop in the context of the internal and external environment. Inevitably, possible changes that may occur can pose a threat or offer opportunities for organizations. The organization is working to take advantage of these possibilities and resources available to seize opportunities and control threats throughout the work. It also aims to anticipate the future through precise planning in order to achieve the goals of the organization and the objectives of its employees. There is no doubt that competent managers are those individuals who set the strategic objectives for their organization using various methods and their power within the organization which enables them to set such objectives. 
Competent managers plan, set goals, coordinate work, give guidance and have control of implementation in order to achieve the tactical and strategic objectives.

Job involvement is a key and an important issue for understanding organizational behavior due to its significant role involving job involvement as a link between the level of productivity, needs of workers and the quality of career of workers. Generally, job involvement as a concept, reflects the importance of the role that the job plays in the individual's life in addition to the readiness of that individual to maintain that job and make every effort to meet its requirements.

Based on this, identifying and achieving strategic objectives in organizations could be achieved through the organizational power and job involvement of managers. This is what the researcher throughout this article has analyzed. Firstly, these variables have been addressed theoretically followed by a discussion of the relationship and its impact between these variables. The results have been obtained in such a way that has helped to reach a set of results and recommendations.

\section{The Study Problem}

Organizational power is one of the most important concepts of contemporary organizations. It occupies a prominent position in the minds of the leaders of many organizations. Job involvement is a bright spot for leaders and managers of organizations who care about the future of the organization and are willing to invest their efforts in their favor in order to achieve organizational strategic objectives. Competent and immersive managers in their jobs, organizations and societies are individuals who set the strategic objectives of the organization in a range of ways using their power that enables them to develop strategic objectives, as well as monitor the implementation of these objectives. As the researcher did a follow-up on the private hospitals in Erbil city, Kurdistan region of Iraq, he notes that there is a significant gap in the level of organizational power and job involvement experienced by the private hospitals managers and the role it plays in private hospitals when achieving their strategic objectives. Based on the above, the study problem can be formulated with the following research questions:

1. What is the reality of the relationship between organizational power and job involvement in private hospitals in Erbil city?

2. Is there is a positive correlation between the organizational power and job involvement through its multiple dimensions?

3. Does organizational power and job involvement have an impact on achieving strategic objectives?

\section{The Significance of the Study}

1. This study aims to attract researchers' attention to discover more about the relationship between the study variables and to present multiple concepts and ideas about the study variables: organizational power, job involvement and achieving strategic objectives.

2. This study is the first of its kind at the level of the Kurdistan region and Iraq deals with the influence on the relationship between organizational power and job involvement in achieving strategic objectives in private hospitals in Erbil city. It is therefore hoped that this study will provide a new scientific addition that may contribute to enriching the local research database.

3. The significance of this study is to assist administrative leaders in private hospitals to identify the relationship between organizational power and job involvement in achieving strategic objectives. In 
light of local and global challenges, hospitals are trying to find new mechanisms for competition as a prerequisite for survival in the provision of health services as well as in the fields of growth and profit. Therefore, the current study is trying to add an economic importance to enable hospitals to provide and develop high-quality health services to achieve their strategic objectives.

\section{The Objectives of the Study}

The main objective of this study is to examine the nature of the relationship between organizational power and job involvement and their impact on achieving strategic objectives in private hospitals in Erbil city. This objective can be achieved through the following:

1. Presenting a conceptual framework for organizational power, job involvement and achieving strategic objectives in a theoretical philosophical framework. This aims to explain the nature of the relationship between organizational power and job involvement and their impact on the achievement of strategic objectives in private hospitals in the Erbil city.

2. Presenting a study framework model that tests the relationship and influence between study variables. Moreover, identify the impact of organizational power and job involvement on the achievement of strategic objectives in private hospitals in Erbil city.

3. By reaching results, recommendations can be formulated and provided in order to help administrative leaders in private hospitals to achieve and develop their strategic objectives.

\section{The Study Framework and Its Hypotheses}

The following figure shows the study framework that is formulated based on questions raised from the study problem that includes three main variables (organizational power, job involvement and strategic objectives).

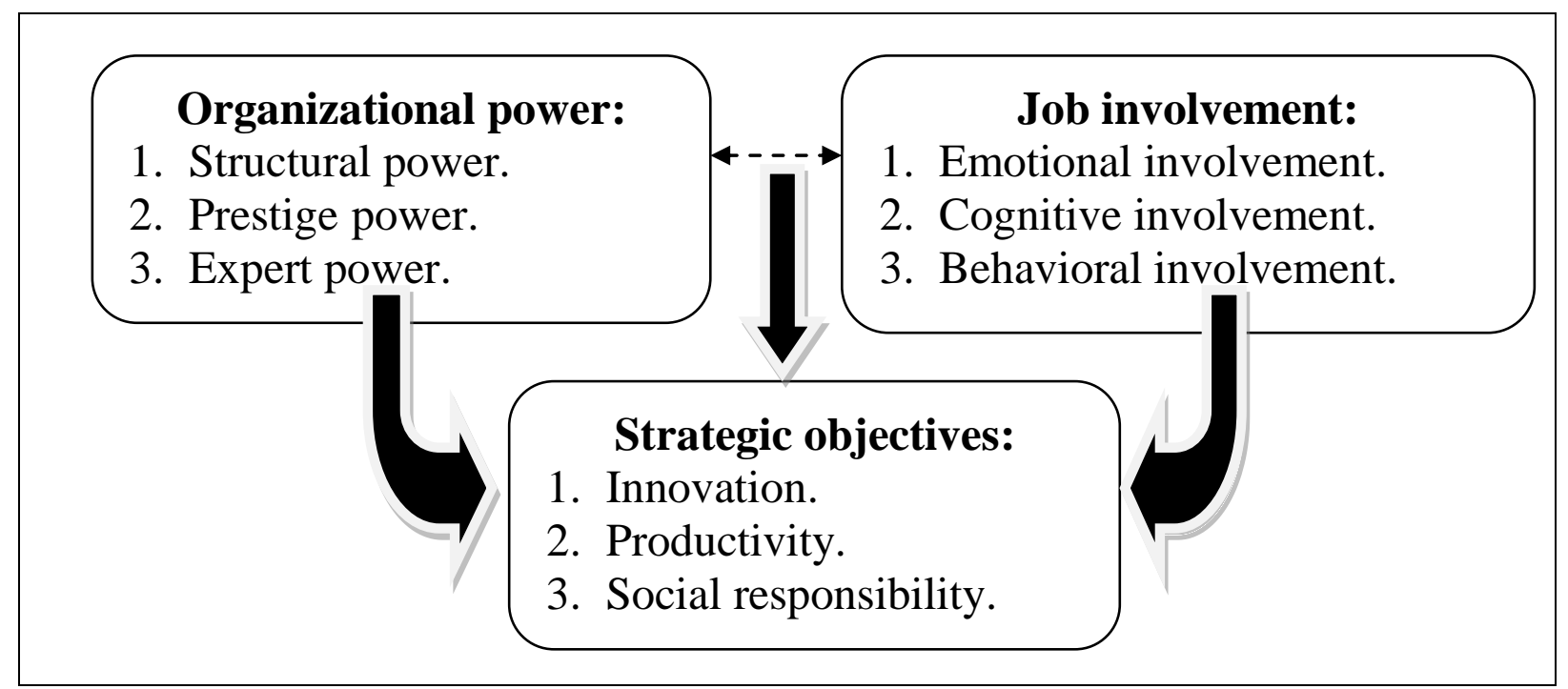

Figure (1) study framework 
The study framework reveals a set of hypotheses as follows:

1. There is a significant positive correlation between organizational power and job involvement.

2. There is a statistically significant impact of organizational power on achieving strategic objectives.

3. There is a statistically significant impact of job involvement on achieving strategic objectives.

4. There is a statistically significant impact on the relationship between organizational power and job involvement in order to achieve strategic objectives.

\section{Methodology}

This study adopts the analytical descriptive approach by relying on primary and secondary sources. Books and published studies were reviewed in order to prepare the theoretical framework of this study. On the applied side, the questionnaire was used to collect data and was distributed to the study sample. The study sample consists of (142) managers who are general managers and supervisors at private hospitals in the Erbil city. The collected data was analyzed through the Statistical Program of (SPSS) and other appropriate statistical methods were used to achieve the results. The reliability coefficient of the internal consistency of all the questions of the questionnaire was calculated according to the Cronbach Alpha coefficient. The Cronbach Alpha coefficient results for all the questions were (0.887), organizational power (0.805), job involvement (0.797), and strategic objectives (0.825). The results of the descriptive statistical analysis of the data, which include the mean and the standard deviations of all the dimensions, are based on the Likert scale.

\section{Literature Review}

\section{The Organizational Power}

Power has occupied human interest since ancient times and is still of great interest, although it is intangible, the results of which can be felt in social organizations. Power is one of the most controversial concepts of social science addressed by many academics and researchers in the field of administrative sciences since it is an important phenomenon with a direct and indirect impact in the field of movement and performance of organizations. The definitions that academics and researchers have presented on the concept of organizational power have varied according to their different directions and their perceptions of its variables. Organizational Power is the ability to acquire human, financial, and informational resources to organize business (Kreitner \& Kinicki, 2007). It is the ability to control individuals and recommend appropriate behavior to reach a certain objective (Vidanapathirana, 2016). The organizational power is the power of (A) on (B), in which (B) works under the supervision of (A), A and B can be described as individuals, groups or organizations (Hach, 2006). It is a relationship between individuals, which means that an individual is able to make order to other individuals what they not wish to do voluntarily (Roberts \& Hunt, 1991). It is the ability possessed by an individual, which they can change the behavior or directions of others towards the destination he/she wishes. It can be concluded from this that organizational power is the power of the individual to influence others through the official position 
that he/she occupies in the organizational structure in order to achieve the strategic objectives of the organization.

There was no agreement between academics and researchers in the field of administrative sciences in general and the organization theory in particular on specific sources of power. This variance exists because there are multiple perspectives in the study of organizational power sources. Hodge \& Anthony (1991) select experience, force, legitimacy, reference, reward, link, and information as organizational power sources. Finkelstein (1992) classified organizational power sources as structural strength, force of experience, and force of status. Ivancevich \& Matteson (2002) select the organizational power sources as reward, legitimacy, reference, coercion, and information. Shermerhorn et al. (2000) classified organizational power into two groups. The first group being the power of the position includes the power of reward, coercive power, and legitimate power. The second group is the personality power that includes experience power, mental persuasion power, and reference power. This study selects structural power, prestige power, and expert power as organizational power sources because they are consistent with the nature and objectives of the study.

Structural Power: This source is based on the formal organizational structure. Managers who have a legal right in exercising the effect they are in an influential position (Brookes, 2013). This power allows the manager to manage ambiguity through control and set organizational goals. It is considered to be legitimate power because it derives from the post held by the manager in the hierarchy of the organization. Structural power sources include decision-making power, resources power, and information power (Yukl, 2006).

Prestige Power: It is the reputation of the managers along with the degree of respect and appreciation obtained. It is the kind of power that belongs to individuals' characters and personalities. Achieving prestige power needs intelligence, experience, acceptance from others and achieving expectations (Torelli, \& Shavitt, 2010).

Expert Power: This type of power depends on the experience and experiments that the individual gains through specialization or skill and knowledge of the experiences he has experienced. It is the ability to provide the best solutions to problems and make sound decisions. Expert Power can be achieved through the manager's knowledge or skills and the realization and knowledge of others with the manager's knowledge through the provision of presenting information and substantive views to the organization (Yukl, 2006). This source has become more important after paying attention to the importance of intellectual capital and its influential role in increasing the effectiveness of contemporary organizations (Drummond, 2000).

\section{Job Involvement}

The topic of job involvement in recent times is one of the researchers' interest topics in the field of human resource management and organizational behavior as it is one of the most significant issues to be considered in order to understand the behavior of the individual within business organizations. In addition to the interpretation of many behavioral variables such as (absence, performance, satisfaction, and nature of work). An individual that is involved in his/her job is considering to be an individual who views his/her work as the most important part of his/her life. Individuals who are involved in work are positive individuals who are interested, enthusiastic towards their jobs and are always ready to go the extra mile and give their effort to carry out the work to their full capacity. Hence, job involvement focuses the relationship between work and happiness which encourage individuals to practice positive behavior as well as contribute effectively to the achievement of the organizations' objectives. Job involvement is the degree to which an individual is connected to their job that affects performance in various areas of 
individuals' life (Bhatia et al, 2012). It is the degree to which an individual integrates into the job that he/she exercises and senses its importance (Chughtai, 2008).

The characteristics of job involvement includes the following set of factors:

- Personal characteristics that represent personal circumstances between individuals such as motivation, values, trends, and gender.

- Job characteristics, such as motivation, job independence, diversity, task descriptions, and feedback.

- Social characteristics, such as working with others, sharing decisions, and feeling of success.

The dimensions of job involvement are emotional involvement, cognitive involvement, and behavioral involvement. Emotional involvement refers to how strong an individual enjoys working or how much an individual loves his/her work. Cognitive involvement refers to the strength of the individual's participation in the jobs' decision-making. Behavioral involvement refers to a behavioral intent, out of job behavior, and how an individual views their job after leaving.

\section{The Strategic Objectives}

The top management sets its strategic objectives in the organization. The manager has a degree of power derived from a variety of sources to influence decision-making and can determine the objectives through various power whether it is the power of the organizational structure, personal and/or experience power in influencing others to make decisions and achieve strategic goals to improve the long-term market situation and competitiveness of the organization.

Strategic decisions on the selection of counterparties are always the focus of most enterprises leadership. Strategic objectives represent the core and first component of the strategic management process (Brookes, 2013). It is the intent behind decisions which determine the direction of the organization and its activities. Strategic objectives are the desired outcomes of individuals, groups and organizations. It is a desired and specific target of the organization, guiding approach to the strategic management process, and measurement of performance that the organization seeks to reach effectively. Peter Druker suggests that businesses need to define targets that relate only to the target results areas. These are areas where performance or results directly affect the continuation and prosperity of an organization's activity. These areas include profitability, market position, innovation, productivity, physical and financial resources, management efficiency, performance and employee trends, and overall responsibility. The strategic analysis and the process of decision-making have to be reasonably detailed, since presently, it corresponds to mere "choosing a strategy (Vorobyov, 2019).

Strategy is a position - specifically a means of locating company in an environment. The ability to innovate is the ability to generate new ideas that can meet perceived needs or respond to opportunities by the organization. This phenomenon is essential for the long-term success of the organization. As it contributes to the beginning of change in the organization because individuals, and groups are working in an environment of innovation, creativity and the application of new ideas.

The focus on productivity targets may be more appropriate when one of the factors of success is to develop a special cost advantage or prevent a competitor from offering the same feature. Productivity is the relationship between a particular result and the means by which it is used in its production. 
Productivity includes the goods and services produced in each unit of labor and capital or both. Many organizations recognize their social responsibility by adopting goals or policies. One of the factors driving this is working to achieve long-term profits through improving perceptions of consumers, suppliers and public opinion, which in turn affects the long-term status of the organization. Social responsibility is the degree to which the manager and the organization carry out their activities to protect society from seeking the direct technical and economic benefits of the organization.

\section{Results and Findings}

Table (1) shows the values of means, standard deviations and the coefficient of variation of the organizational power dimensions from the perspective of managers in private hospitals. The table reflects a general accounting average of mean (3.79) which is a high mean and a relative importance of (75.97\%), the general average value of $(\mathrm{T})(7.221)$ these results confirm the existence of an organizational power involved in private hospitals.

Table (1) results of Organizational power analysis

\begin{tabular}{|l|c|c|c|c|}
\hline $\begin{array}{l}\text { Organizational power and its } \\
\text { dimensions }\end{array}$ & Mean & $\begin{array}{c}\text { Standard } \\
\text { deviation }\end{array}$ & $\begin{array}{c}\text { Relative } \\
\text { importance }\end{array}$ & T Value \\
\hline Structural power & 3.95 & .804 & $79.04 \%$ & 9.552 \\
\hline Prestige power & 3.46 & 1.108 & $69.24 \%$ & 3.447 \\
\hline Expert power & 3.98 & .837 & $79.64 \%$ & 8.664 \\
\hline Organizational power & 3.79 & .916 & $75.97 \%$ & 7.221 \\
\hline
\end{tabular}

At the level of organizational power dimensions, table (1) shows that expert power is the most significant dimension that contribute to the enhancement of the organizational power for hospitals in the study with a general accounting average of mean (3.89) which is a high mean with a relative importance of $(79.64 \%)$. The reason for this is the managers' experience that contributes to supporting the hospital's work policies along with extensive experience obtained by managers in previous work positions. Structural power has been shown to be the second most significant dimension that contributes to the enhancement of the organizational power for the hospitals due to managers and the importance of the type of tasks that have positive results in their own work in the hospital along with excellent skills and abilities to influence others. Prestige power is the third most significant dimension that contributes to the enhancement of the organizational power for the hospitals in this particular study.

Table (2) reflects a general accounting average of job involvement's mean (4.014) which is a high mean with a relative importance of $(80.29 \%)$ and the general average value of (T) as (10.187). These results confirm the existence of job involvement experienced in private hospitals. 
Table (2) results of Job involvement analysis

\begin{tabular}{|l|c|c|c|c|}
\hline $\begin{array}{l}\text { Job involvement and its } \\
\text { dimensions }\end{array}$ & Mean & $\begin{array}{c}\text { Standard } \\
\text { deviation }\end{array}$ & $\begin{array}{c}\text { Relative } \\
\text { importance }\end{array}$ & T Value \\
\hline Emotional involvement & $\mathbf{3 . 8 9}$ & $\mathbf{. 7 2 2}$ & $\mathbf{7 7 . 8 4 \%}$ & $\mathbf{9 . 2 4 1}$ \\
\hline Cognitive involvement & $\mathbf{4 . 0 0 6}$ & $\mathbf{. 8 4 2}$ & $\mathbf{8 0 . 1 2 \%}$ & $\mathbf{9 . 0 9 4}$ \\
\hline Behavioral involvement & $\mathbf{4 . 1 4 6}$ & $\mathbf{. 6 6 4}$ & $\mathbf{8 2 . 9 2 \%}$ & $\mathbf{1 2 . 2 2 8}$ \\
\hline job involvement & $\mathbf{4 . 0 1 4}$ & $\mathbf{. 7 4 2}$ & $\mathbf{8 0 . 2 9 \%}$ & $\mathbf{1 0 . 1 8 7}$ \\
\hline
\end{tabular}

At the level of job involvement dimensions, table (2) shows that behavioral involvement is the most significant dimension that contributes to the enhancement of the behavioral involvement with an average mean of (4.146). The reason for this is that there is a high commitment towards the hospital and the managers are interested in its development along with follow-up observations, complaints or developments concerning the hospital. Furthermore, the cognitive involvement as the second most significant dimension contributing to job involvement is due to the managers' commitment to working hours and to thinking about the job even after the working day is over. Emotional involvement is the third most significant dimension that contributes to job involvement. The reason for this is due to the mangers perspectives on working in the hospital (that being the primary concern for them) and that the job fully satisfies their needs as well as cultivating good relationships between individuals in the hospital.

Table (3) reflects a general accounting average of strategic objectives' mean (3.87) which is a high mean with a relative importance of $(78 \%)$ with an average value of $(\mathrm{T})$ as (7.959). These results confirm the existence of strategic objectives experienced in private hospitals in this particular study.

Table (3) results of strategic objectives analysis

\begin{tabular}{|l|c|c|c|c|}
\hline $\begin{array}{l}\text { Strategic objectives and its } \\
\text { dimensions }\end{array}$ & Mean & $\begin{array}{c}\text { Standard } \\
\text { deviation }\end{array}$ & $\begin{array}{c}\text { Relative } \\
\text { importance }\end{array}$ & T Value \\
\hline Innovation & $\mathbf{4 . 2 0}$ & $\mathbf{. 7 1 0}$ & $\mathbf{8 4 . 0 8 \%}$ & $\mathbf{1 2 . 1 5 9}$ \\
\hline Productivity & $\mathbf{3 . 8 2}$ & $\mathbf{. 9 5 1}$ & $\mathbf{7 6 . 3 2 \%}$ & $\mathbf{6 . 4 3 6}$ \\
\hline Social responsibility & $\mathbf{3 . 6 1}$ & $\mathbf{. 9 1 7}$ & $\mathbf{7 3 . 6 \%}$ & $\mathbf{5 . 2 8 3}$ \\
\hline Strategic objectives & $\mathbf{3 . 8 7}$ & $\mathbf{. 8 5 9}$ & $\mathbf{7 8 \%}$ & $\mathbf{7 . 9 5 9}$ \\
\hline
\end{tabular}

At the level of strategic objectives dimensions, table (3) shows that innovation is the most significant dimension that contributes to the enhancement of strategic objectives with an average mean of (4.20). The reason for this is that the hospital administration often seeks to find new ways of performing its activities, expand the use of modern skills and influence customers behavior and values to develop customer growth. Productivity is the second most significant dimension that contributes to the enhancement of strategic objectives due to the attention of the hospital administration on the employees working in the hospital, as they have a significant role in raising productivity of the hospital as well as careful planning of their human resources to make a healthy balance between work requirements and training policies. Social responsibility is the third most significant dimension that contributes to the enhancement of the strategic objectives. The reason is that hospital administration seeks to develop its 
relations with other hospitals, cooperatives, and other organizations as well as provide equal opportunities for recruitment.

\section{Examining the Correlation between the Study Variables}

The first hypothesis states that there is a significant positive correlation between organizational power and job involvement. Pearson Correlation was used in order to examine this hypothesis which indicates a significant and medium correlation $(\mathrm{r}=.505)$ between organizational power and job involvement at the significant value of (0.000). Nevertheless, the existence of a positive correlation exists between organizational power and job involvement dimensions (emotional involvement, cognitive involvement, and behavioral involvement $)(\mathrm{r}=.387),(\mathrm{r}=.487)$, and $(\mathrm{r}=.413)$ respectively.

\section{Examining the Impact between the Study Variables}

In order to examine the second, third, and fourth hypotheses, the multiple regression analysis was used to identify the impact between the research variables. The results of the multiple regression model indicate that organizational power and job involvement independently have an impact on achieving strategic objectives. This is supported by the value of (F) calculated that equal to (18.957), and (22.455) respectively which is greater than the value of $(F)$ tabulated that equal to $(2.835)$. The coefficient of $\left(R^{2}\right)$ is equal to (0.215) and (0.297) respectively, which refers to the ability of the organizational power and job involvement independently in explaining the achievement of the strategic objectives of about $21.5 \%$ and $29.7 \%$ respectively.

The results show that the relationship between organizational power and job involvement affects the achievement of strategic objectives. This is supported by the value of $(\mathrm{F})$ calculated to equal to (32.684), which is greater than $(\mathrm{F})$ tabular value (2.835) at the significant level (0.001). The coefficient of $\left(\mathrm{R}^{2}\right)$ is equal to $(0.325)$ which refers to the ability of the relationship between organizational power and job involvement in explaining the achievement of the strategic objectives of about $32.5 \%$.

Table (4) the impact between study variables

\begin{tabular}{|l|c|c|c|}
\hline & \multicolumn{3}{|c|}{ Achieving the strategic objectives } \\
\hline Organizational power & $($ F) calculated & $($ F) tabulated & $\mathbf{R}^{\mathbf{2}}$ \\
\hline Job involvement & 18.957 & 2.835 & 0.215 \\
\hline $\begin{array}{l}\text { The relationship between organizational } \\
\text { power and job involvement }\end{array}$ & 22.455 & 2.835 & 0.297 \\
\hline & 32.684 & 2.835 & 0.325 \\
\hline
\end{tabular}




\section{Discussion and Conclusion}

The results of the descriptive analysis showed a high level of structural power and expert power of organizational power dimensions. These results indicate that private hospitals have a good organizational power over its strategies along with the provision of services to customers. The level of job involvement and its three dimensions (emotional, cognitive, and behavioral) of the managers in the private hospitals in Erbil city is positive and high due to that the managers involvement in their jobs. Moreover, there is a sense of psychological comfort to their jobs because of hospital policies that lead to psychological and job stability that result in a high degree of involvement in their jobs and duties. The level of achieving strategic objectives which include (innovation, productivity, and social responsibility) is positive. It can be said that administrative leaders in private hospitals are setting strategic objectives. The managers have derived power from a variety of sources to influence decision-making, setting objectives, influencing others, and achieving strategic objectives.

\section{Recommendations}

1. Organizations have to activate the organizational power and put it into practice for this will play a significant role in increasing the level of job involvement through working to increase the awareness of administrative leaders.

2. Identifying organizational factors that can lead to the development of organizational level and by providing incentives, an increased rate in job involvement could be achieved.

3. Organizations need to work on the development of managers' job involvement by assessing the needs of the managers and their personal objectives.

4. Organizations have to increase the awareness of the importance of achieving the strategic and future objectives that have positive results for the organization as well as to maximize the values of the manager's job involvement since it has recently been considered as the most important subject of managing human resources. 


\section{References}

Bhatia A, Deep G \& Sachdeva S, (2012). Analyzing the role of job involvement on organisational effectiveness: An empirical study among the employees of Punjab national bank, International journal of Computing \& Business research.

Brookes, M. (2013). Varieties of Power in Transnational Labor Alliances: An Analysis of Workers' Structural, Institutional, and Coalitional Power in the Global Economy. Labor Studies Journal, 38(3), 181-200.

Chughtai, A. A. (2008). Impact of job involvement on in-role job performance and organizational citizenship behaviour. Journal of Behavioral and Applied Management, 9(2), 169-183.

Drummond, H. (2000). Introduction to organizational behavior. Oxford University Press, Oxford.

Finkelstein, S. (1992). Power in Top Management Teams: Dimensions, Measurement, and Validation. The Academy of Management Journal, 35(3), 505-538.

Hach, M. (2006). Organization Theory: Modern, Symbolic, and Postmodern Perspectives. Oxford University Press, Oxford.

Hodge, B. \& Anthony, W. (1991). Organization theory: A strategic Approach. Boston: Allyn and Bacon.

Ivancevich, J., M., \& Matteson, M., T. (2002). Organizational behavior and Management. New York, NY: McGraw-Hill Irwin.

Kreitner. R. \& Kinicki. A. (2007). Organizational Behavior. 7th ed. McGraw-Hill Inc. New York.

Roberts, K.H., \& Hunt, D.M. (1991). Organizational Behavior. Boston: PWS Publishing Company.

Schermerhorn,J., Hunt,j.and Osborn, R. (2000). Organizational Behavior, John Wiley and Sone, New York.

Torelli, C. J., \& Shavitt, S. (2010). Culture and Concepts of Power. Journal of Personality and Social Psychology, 99(4), 703-723.

Vidanapathirana, T. (2016). Non-Mediated Power Sources In a Collectivist Context: Role of NonMediated Power Sources in Managing the Performance of Tea Producers Marketing Channels. International Journal of Management and Commerce Innovations, 3(2), 444-450.

Vorobyov, A. (2019).A Unified Methodology of Strategic Management and a Knowledge Management Model. TEM Journal, 8(2), 554-563.

Yukl, G. (2006). Leadership in organizations. 6th Ed, Upper Saddle River, NJ: Pearson-Prentice Hall.

\section{Copyrights}

Copyright for this article is retained by the author(s), with first publication rights granted to the journal.

This is an open-access article distributed under the terms and conditions of the Creative Commons Attribution license (http://creativecommons.org/licenses/by/4.0/). 